\title{
Referrals revisited: a clinical audit
}

\section{Swati Dubey*, Sumita Mehta, Sonam Singh, Anshul Rohatgi}

Department of Obstetrics and Gynecology, Babu Jagjiwan Ram Memorial Hospital, Jahangirpuri, New Delhi, India

Received: 12 September 2017

Accepted: 05 October 2017

\author{
*Correspondence: \\ Dr. Swati Dubey, \\ E-mail: minidubey23@gmail.com
}

Copyright: () the author(s), publisher and licensee Medip Academy. This is an open-access article distributed under the terms of the Creative Commons Attribution Non-Commercial License, which permits unrestricted non-commercial use, distribution, and reproduction in any medium, provided the original work is properly cited.

\begin{abstract}
Background: Pregnancy and childbirth are physiological processes; however, severe maternal morbidity can complicate certain pregnancies, deliveries and puerperium. To prevent maternal/ neonatal morbidity and mortality, the high-risk category needs timely identification and intervention and if required, prompt referral to higher centres where HDU/ICU level of care is provided. The present study was a clinical audit of obstetric referrals.

Methods: A clinical audit of all obstetrics referrals done at BJRM (secondary level facility) from $1^{\text {st }}$ May to $31^{\text {st }}$ October 2016. The cases were analysed with respect to demographics, indications for referral and barrier to services.

Results: Referral rate of our hospital was $6.52 \%$. Mean age of women referred was 24.16 years. The associated risk factors were PIH in $36.17 \%$, anaemia in $34.04 \%$, followed by thrombocytopenia and diabetes in pregnancy. Majority of referrals were done in women during labour $93.94 \%$ while only $3.03 \%$ referrals during post-partum period. Most common indication was MSL with foetal distress 20.96\%, followed by hypertensive disorders in pregnancy $16.93 \%$. Other indications were $\mathrm{APH}$, malpresentation, $2^{\text {nd }}$ stage arrest and cord prolapse. The main barriers to providing services at our institute were unavailability of 24 hours OT services, blood bank and ICU care.

Conclusions: Standard referral protocol and well-defined linkages need to be established so as to have better coordination between the referral units and tertiary centres.
\end{abstract}

Keywords: Barrier in referral service, High risk pregnancy, Obstetric referral, Referral protocol

\section{INTRODUCTION}

Pregnancy and childbirth are physiological processes; however, severe maternal morbidity can complicate certain pregnancies, deliveries and puerperium. Approximately $30 \%$ of such obstetric cases belong to this high-risk category which collectively accounts for 70$80 \%$ of maternal and perinatal morbidity and mortality. ${ }^{1}$

According to WHO, in comparison to a developed country, a woman in a developing country is at 33 times higher risk of dying from obstetrical causes, in her lifetime. ${ }^{2}$ UNICEF data estimates that about 800 women die every day due to preventable obstetric causes and 20 per cent of these women belong to India. India's share of global maternal deaths is $17 \%$, with 55,000 women dying of preventable obstetric causes annually. 3,4
Maternal Mortality Ratio (MMR) reflects the overall health care system of the society and their attitude towards women. India has failed to achieve the Millennium Development Goal (MDG) of decreasing the MMR by $75 \%$ by the year 2015 as compared to the year 2010, as reflected in MMR, which reduced from 215 in 2010 to 174 in $2015 .{ }^{3,4}$

To prevent maternal/neonatal mortality, the high-risk category needs timely identification and intervention and if need be, prompt referral to higher centres where HDU/ICU level of care is provided. The health care system needs to be ready to manage such high-risk cases with a positive outcome. In our country, healthcare is provided at primary, secondary and tertiary level; therefore, a strong, structured referral system assumes prime importance in meeting this challenge. 
The present study was done to analyse the indications for referral and barriers in providing optimal obstetric care at district level hospitals.

\section{METHODS}

A clinical audit of all obstetrics referrals was done at Babu Jagjiwan Ram Memorial hospital (BJRM), Delhi (a secondary level facility) from $1^{\text {st }}$ May to $31^{\text {st }}$ October 2016 over a period of 6 months. It was a prospective, proforma based observational study where data from 132 cases was collected.

All pregnant women who were referred to tertiary hospital from our institute (Labour room and ANC OPD) during the study period were included and analysed using a proforma. All pregnant women with age less than 20 year and more than 35 years were taken as high-risk age group. Those pregnant women that were seen at BJRM hospital outside the study period, or referred from outside or those who requested to continue to be seen at BJRM Hospital due to other reasons were excluded.

The proforma was designed to include maternal demographics like age, gravidity, period of gestation at presentation and associated medical conditions. Salient features in history and examination were noted and baseline and specific investigations including ultrasonography were recorded. A note was also made of indications for referral, whether the reference was ante/intra/post-partum, date and time interval between admission and referral and pre-referral treatment. Barriers for providing optimal obstetric care at our institution were also recorded. Data entry and analysis were done in MS excel.

\section{RESULTS}

A total of 2023 obstetrics cases were admitted in labour room of BJRM hospital during the study period. Out of this, 132 cases were referred, thus making the referral rate as $6.52 \%$.

Mean age of women referred was 24.16 years. In this category, $9(6.81 \%)$ women belonged to the high-risk age group, out of which $7(5.30 \%)$ women were less than 20 years of age and $2(1.51 \%)$ women were more than 35 years (Table 1).

Parity of women influences the state of current pregnancy and in the present study, there were 77 (58.33\%) primipara and $55(41.66 \%)$ multipara (Table 1).

Out of the 132 referrals, $106(80.30 \%)$ cases were referred at term, $3(2.27 \%)$ cases were referred at less than 28 weeks period of gestation (POG), of which, 2 cases were of eclampsia and 1 case was ruptured gravid horn of bicornuate uterus in shock and 3 (2.27\%) women were of less than 20 weeks POG, which were referred for ruptured ectopic pregnancy (Table 1).
Table 1: Maternal demographics.

\begin{tabular}{|lll|}
\hline Age & No. $(\mathbf{n = 1 3 2})$ & $\%$ \\
\hline$\leq 20$ & 23 & 17.42 \\
\hline $21-25$ & 75 & 56.82 \\
\hline $26-30$ & 28 & 21.21 \\
\hline $31-35$ & 04 & 04.55 \\
\hline$>35$ & 02 & 01.51 \\
\hline Gravida & No. $(\mathbf{n}=\mathbf{1 3 2})$ & $\mathbf{\%}$ \\
\hline P0 & 77 & 58.33 \\
\hline P1 & 34 & 25.76 \\
\hline P2 & 15 & 11.36 \\
\hline P3 & 3 & 02.27 \\
\hline P4 & 3 & 02.27 \\
\hline Associated medical disorders & No. $(\mathbf{n}=\mathbf{1 3 2})$ & $\mathbf{\%}$ \\
\hline Anaemia (moderate and severe) & 16 & 34.04 \\
\hline HTN/PIH & 17 & 36.17 \\
\hline Thrombocytopenia & 4 & 08.51 \\
\hline Hypothyroidism & 2 & 04.26 \\
\hline Diabetes & 2 & 04.26 \\
\hline Fever & 5 & 10.64 \\
\hline IHCP & 1 & 02.12 \\
\hline POG (weeks) & No. $(\mathbf{n}=\mathbf{1 3 2})$ & $\mathbf{\%}$ \\
\hline$\leq 20$ & 3 & 02.27 \\
\hline $20+1-27+6$ & 3 & 02.27 \\
\hline $28-36+6$ & 20 & 15.15 \\
\hline $37-40$ & 69 & 52.27 \\
\hline$>40$ & 37 & 28.03 \\
\hline
\end{tabular}

Table 2: Indications for referral.

\begin{tabular}{|c|c|c|}
\hline Indication & $\begin{array}{l}\text { No. of cases } \\
N=132\end{array}$ & Percentage \\
\hline Intra partum & $124(n=124)$ & 93.94 \\
\hline MSL+FD & 26 & 20.96 \\
\hline FD & 14 & 11.29 \\
\hline $\begin{array}{l}\text { Thick MSL in early } \\
\text { labour }\end{array}$ & 11 & 8.87 \\
\hline Malpresentation & 13 & 10.48 \\
\hline -Breech & 11 & 8.87 \\
\hline Mentoposterior & 2 & 1.61 \\
\hline $\begin{array}{l}\text { Severe PE/ HELLP/ } \\
\text { impending eclampsia/ } \\
\text { eclampsia }\end{array}$ & 21 & 16.93 \\
\hline Arrest of $2^{\text {nd }}$ stage & 8 & 6.45 \\
\hline Protracted labour & 15 & 12.10 \\
\hline Abruption & 7 & 5.65 \\
\hline Cord prolapse & 5 & 4.03 \\
\hline Thrombocytopenia & 4 & 3.23 \\
\hline Antepartum & 4 & 3.03 \\
\hline Ectopic & 3 & 75 \\
\hline $\begin{array}{l}\text { Ruptured gravid horn of } \\
\text { Bicornuae uterus }\end{array}$ & 1 & 25 \\
\hline Post-partum & 4 & 3.03 \\
\hline Atonic PPH & 2 & 50 \\
\hline Traumatic PPH & 1 & 25 \\
\hline Severe Anemia+TCP & 1 & 25 \\
\hline
\end{tabular}

Out of the 132 cases, most of the referrals were intrapartum $124(93.94 \%)$ and $4(3.03 \%)$ women each were referred during antepartum and postpartum period. 
The common indication for referral during intrapartum period was meconium stained liquor (MSL) with foetal distress (FD) $26(20.96 \%)$, hypertensive disorders of pregnancy $21(16.93 \%)$, protracted labour $15(12.10 \%)$, foetal distress $14(11.29 \%)$, malpresentation $13(10.48 \%)$, thick MSL in early labour $11(8.87 \%)$, arrest of $2^{\text {nd }}$ stage $8(6.45 \%)$, abruption $7(5.65 \%)$, cord prolapse $5(4.03 \%)$ and thrombocytopenia $4(3.23 \%)$. A total of $4(3.03 \%)$ women were referred during postpartum period, out of which $2(50 \%)$ cases were of atonic post-partum haemorrhage $(\mathrm{PPH})$ and $1(25 \%)$ case each of traumatic $\mathrm{PPH}$ and postnatal severe anaemia with thrombocytopenia. Antepartum referral cases included 3 (75\%) cases of ruptured ectopic pregnancy and 1 (25\%) case of ruptured gravid horn of bicornuate uterus in shock (Table 2).

Most of the patients 59 (44.69\%), were referred within 612 hours from the time of admission while 17 (12.87\%) women were referred after 12 hours, and 16 (12.12\%) referrals were done after 24 hours (Table 3).

Table 3: Time interval between admission and referral.

\begin{tabular}{|lll|}
\hline $\begin{array}{l}\text { Time interval } \\
\text { (TOA-TOR) }\end{array}$ & $\begin{array}{l}\text { Number of } \\
\text { cases }(\mathbf{n = 1 3 2})\end{array}$ & Percentage \\
\hline$<6$ hours & 40 & 3.30 \\
\hline 6-12 hours & 59 & 44.69 \\
\hline 12-24 hours & 17 & 12.87 \\
\hline$>1$ day & 16 & 12.12 \\
\hline
\end{tabular}

In the present study, the most common barrier to dispense optimal emergency obstetric care was unavailability of emergency OT services in $82.57 \%$, followed by unavailability of blood bank in $19.69 \%$ cases, lack of ICU care in $8.33 \%$ cases and lack of NICU care in $6.06 \%$ cases (Table 4).

Table 4: Barriers to optimal care.

\begin{tabular}{|lll|}
\hline $\begin{array}{l}\text { Barriers to optimal } \\
\text { obstetric care }\end{array}$ & $\begin{array}{l}\text { No. of cases } \\
(\mathbf{n = 1 3 2})\end{array}$ & \begin{tabular}{l} 
Percentage \\
\hline Blood bank
\end{tabular} \\
\hline EMOT & 26 & 19.69 \\
\hline ICU Care & 109 & 82.57 \\
\hline NICU Care & 11 & 8.33 \\
\hline
\end{tabular}

\section{DISCUSSION}

Maternal and neonatal outcomes can be improved significantly if barriers to optimal emergency obstetric services can be removed. Most of the load of providing obstetric care in our country is taken up by the peripheral hospitals. But as these institutions lack in terms of human resources and infrastructure, so patients at times need to be referred to higher centers.

Referral rate of our institution was $6.52 \%$ during the study period, which is similar to a study done by Siraj et al $(4.47 \%) .{ }^{5}$ Referral rate was found to be slightly higher $15.2 \%$ in the study done by Patel et al which was done at a PHC and $35 \%$ in the study done by Bhopal SS et al whereas Khatoon A et al found a much higher rate of $40 \%$ in her study. ${ }^{6-8}$

Out of 132 cases referred in this study, the mean age of patient was 24.16 years. There were $9(14.39 \%)$ patients who belonged to high risk age group ( 7 women were adolescent and 2 women were aged $>35$ years). Sirajet al found the mean age to be $27 \pm 5$ years, which is higher than our study population. ${ }^{5}$ This can be due to socioeconomic and cultural factors with prevalence of marriage at an early age in our study area.

$77(58.33 \%)$ primigravida and $55(41.66 \%)$ multigravida patients were referred in this study group. Referral rate was slightly higher for primigravida. Similar rates were seen in the study of Khatoon A et al. ${ }^{8}$

In the present study most of the referrals 124 (93.94\%) were during intrapartum period, followed by antepartum and postpartum period, 4 (3.03\%) women in each group. In the study done by Khatoon et al antepartum referral cases were $10 \%$ and intrapartum were $69 \% .^{8}$ Patel HC et al study found that majority of referrals were during antenatal period $(64.5 \%)$, followed by intranatal $(23.9 \%)$ and postnatal period $(11.6 \%) .{ }^{5}$ Intrapartum referrals were high in the present study as our institution lacks emergency OT services/ICU/HDU and blood bank, whereas antepartum referrals were less as high risk factors were timely identified in antenatal OPD in majority of cases and such patients were managed and referred on OPD basis.

In the present study, the most common cause of referral was MSL with fetal distress in 26 (20.96\%) cases, followed by hypertensive disorders of pregnancy in 21 (16.93\%) women, protracted labour in 15 (12.10\%) women, fetal distress in $14(11.2 \%)$, malpresentation in $13(10.48 \%)$ women and PPH in 3 women $(2.47 \%)$. Similar results were seen in the study done by Khatoon A et al, where common reasons for referral were MSL (78\%), followed by hypertensive disorders of pregnancy (27\%), protracted labour $(20 \%)$ and PPH $(2 \%){ }^{8}$ Qureshi et al found PIH $(32.3 \%)$ as the most common cause of referral. ${ }^{9}$ In yet another study done by Chaturvedi $S$ et al, protracted labour $(38 \%)$ was the most common cause of referral, followed by PIH (7.2\%), PPH (7.8\%) and MSL $(2.8 \%){ }^{10}$

Most of our patients $59(44.69 \%)$ were referred within 612 hours of admission, $40(3.03 \%)$ were referred within 6 hours, while $16(12.12 \%)$ were referred after more than 24 hours. This is because majority of the patients were in labour and early identification of complications and timely referral was emphasized upon. Patients who were referred after 12-24 hours were the ones where antepartum care in the form of steroid cover, building up of hemoglobin in moderate to severely anemic patients, 
control of high BP and stabilization of patients was done. In the study done by Khatoon et al, majority of women reached tertiary care centers within 6-12 hours of referral, $52 \%$ took $12-24$ hours and yet $8 \%$ of patients took more than a day. ${ }^{8}$

In the present study, the most common barrier to dispense optimal emergency obstetric care was unavailability of emergency OT services in $82.57 \%$, followed by unavailability of blood bank in $19.69 \%$ cases, lack of ICU care in $8.33 \%$ cases and lack of NICU care in $6.06 \%$ cases, with the same patient requiring multiple interventions in many cases. In the study by Maskey $\mathrm{S}$ et al, $51.79 \%$ of referred cases required surgical intervention, $18.75 \%$ cases needed ICU care and $25.89 \%$ women were transfused blood/ blood products. ${ }^{11}$

\section{CONCLUSION}

Emergency obstetric care has evolved into HDU (high dependency unit) and obstetric ICU level of care at tertiary level hospitals leaving secondary level hospitals with an urgent need to upgrade with respect to manpower and infrastructure as they serve as the point of first contact with the patient. Infrastructure development in terms of emergency OT services and blood bank at district level hospitals can go a long way in improving maternal/neonatal outcomes and in decreasing the workload on the already overwhelmed tertiary care centres. Also, to bridge the gap between peripheral and tertiary centres, it is essential to have structured referral linkages in place so that the peripheral hospitals can make timely referrals of women in need of specialised care.

Funding: No funding sources Conflict of interest: None declared

Ethical approval: The study was approved by the Institutional Ethics Committee

\section{REFERENCES}

1. Bharti, Vijay K, Amandeep K, Sumit C, Manisha M. Prevalence and correlates of high risk pregnancy in rural Haryana: a community based study. Int J Basic Applied Med Sci. 2013;3(2):212-7.

2. World Health Organization. Global health observatory data (GHO) data. 2017. Available at http://www.who.int/gho/maternal_health/en/

3. Unicef India. What we do- maternal health, 2017. Available at http://unicef.in/Whatwedo/1/MaternalHealth

4. World Health Organization. Trends in maternal mortality: 1990 to 2013. Estimates by WHO, UNICEF, UNFPA, The World Bank and the United Nations Population Division. 2014 Available at: http://apps.who.int/iris/bitstream/10665/112682/2/97 89241507226_eng.pdf

5. Siraj S, Bawar S. An audit of obstetrical referrals from district level hospitals to tertiary level hospitals of KPK. J Postgrad Med Inst. 2016;30(2):160-4.

6. Patel HC, Singh BB, Moitra M, Kantharia SL. Obstetric referrals: scenario at a primary health centre in Gujarat. Natl J Comm Med. 2012;3(4):7114.

7. Bhopal SS, Halpin SJ, Gerein N. Emergency obstetric referral in rural Sierra Leone: what can motorbike ambulances contribute? a mixed-methods study. Matern Child Health J. 2013;17:1038-43.

8. Khatoon A, Hasny SF, Irshad S, Ansari J. An audit of obstetrics referrals to Abbasi Shaheed Hospital. Pak J Surg. 2011;27(4):304-8.

9. Qureshi RN, Sikandar R, Hoodbhoy Z, Bano R, Jabeen N. Referral pattern of emergencies in obstetrics: implications for defining scope of services and policy. J Pak Med Assoc. 2016;66(12):1606-10.

10. Sarika C, Bharat R, Vishal D, Ayesha DC. Quality of obstetric referral services in India's JSY cash transfer programme for institutional births: a study from Madhya Pradesh province. J PLoS One. 2014;9(5):e96773

11. Maskey S. Obstetric Referrals to a Tertiary Teaching Hospital of Nepal. NJOG. 2015;19(1):52-6.

Cite this article as: Dubey S, Mehta S, Singh S, Rohatgi A. Referrals revisited: a clinical audit. Int J Reprod Contracept Obstet Gynecol 2017;6:5118-21. 